2 Tate JR, Ferguson W, Bais R, et al. The determination of the 99th centile level for troponin assays in an Australian reference population. Ann Clin Biochem 2008;45:275-88
School of Medicine, University of Milano, Milano, Italy

Email: giuseppebanfi@supereva.it

DOI: $10.1258 /$ acb.2009.009135

\section{Reliability of cystatin C in estimating renal function in rugby players}

\section{Dear Sir,}

Serum creatinine concentrations in professional athletes are higher than those found in the general population, as demonstrated in a large series of top-level sportsmen competing in eight different sports disciplines. ${ }^{1}$ Cystatin $C$ has been proposed as an alternative to creatinine for assessing glomerular filtration rate (GFR).

We measured serum creatinine concentration in 25 men (age range 22-30 years; mean body mass index [BMI] 27.4 (SD 1.3) $\mathrm{kg} / \mathrm{m}^{2}$ ) belonging to the Italian national rugby team; blood was drawn in January, in the middle of the competitive season, when the psychophysical stress for athletes is at highest level.

Serum creatinine was measured by the Jaffe reaction (Aeroset c8000, Abbott, Chicago, IL, USA; upper limit of normal $110 \mu \mathrm{mol} / \mathrm{L}$ ) and by an enzymatic method (Johnson and Johnson Vitros 950, Johnson and Johnson, Raritan, NJ, USA). Cystatin C was measured nephelometrically (Dade Behring, Marburg, Germany; upper limit of normal $0.95 \mathrm{mg} / \mathrm{L}$ ).

The mean Jaffe serum creatinine concentration was 115 $\mu \mathrm{mol} / \mathrm{L}$ (SD: 13.3), while the mean value using the enzymatic method was $119 \mu \mathrm{mol} / \mathrm{L}$ (SD: 13.3). Twelve/fifteen players had serum creatinine concentrations exceeding $110 \mu \mathrm{mol} / \mathrm{L}$ using the Jaffe/enzymatic assays respectively. The mean cystatin C concentration was $0.85 \mathrm{mg} / \mathrm{L}$ (SD: $0.08)$; no player had a cystatin $C$ concentration exceeding $0.95 \mathrm{mg} / \mathrm{L}$.

Body mass and in particular muscle mass are known to influence serum creatinine concentration. Our data suggest that serum cystatin $\mathrm{C}$ concentration may be a more accurate reflection of GFR in these professional athletes.

\section{DECLARATIONS}

Competing interests: None.

Funding: None.

Guarantor: GB.

Contributorship: GME: analyses of creatinine and cystatin C, discussion and approval of manuscript. GM: recruitment and preparation of subjects, discussion and approval of manuscript. GB and MDF: preparation and editing of manuscript.

\footnotetext{
Giuseppe Banfi $^{1,2}$, Massimo Del Fabbro ${ }^{1,2}$, Gianlodovico Melzi d'Eri ${ }^{3,4}$ and Gianluca Melegati ${ }^{1}$ ${ }^{1}$ IRCCS Galeazzi; ${ }^{2}$ Dipartimento Tecnologie per la Salute, School of Medicine, University of Milano; ${ }^{3}$ Laboratorio Analisi, Ospedale San Paolo; ${ }^{4}$ Dipartimento Scienze Biomediche,
}

\section{REFERENCE}

1 Banfi G, Del Fabbro M. Serum creatinine values in elite athletes competing in 8 different sports: comparison with sedentary people. Clin Chem 2006;52:330-1

\section{Response to Heijboer et al. Ann Clin Biochem 2009;46(3):263-4}

\section{Dear Editor,}

Heijboer et al. ${ }^{1}$ highlighted the potential interference in the Roche free thyroxine (fT4) assay (Roche Diagnostics $\mathrm{GmbH}$, Mannheim, Germany) resulting from ruthenium antibodies. Our laboratory performs approximately 100,000 thyroid profiles per annum. In 2005 we reported to Roche our concerns regarding the high number of increased fT4 results with normal thyroid-stimulating hormone (TSH) concentrations we were observing in euthyroid patients, with fT4 concentrations being normal when repeated using an Auto Delfia assay (Wallac Oy, Turku, Finland) in a neighbouring laboratory. In one case, serum was referred to Roche for further investigation. Roche reported fT4 concentrations of 17.1 and $24.3 \mathrm{pmol} /$ $\mathrm{L}$ with and without a blocking reagent, respectively, confirming the presence of interference against ruthenium.

Between 2005 and June 2007, we identified 11 cases of falsely elevated fT4 concentrations in euthyroid patients. Due to this, in collaboration with Roche, we installed the TOSOH AIA360 analyser (Tosoh Corp., Tokyo, Japan) in June 2007 to confirm fT4 concentrations $>22 \mathrm{pmol} / \mathrm{L}$ locally. Between June 2007 and October 2008 (introduction of lot 151161), we identified a further $33 \mathrm{fT} 4$ results that were significantly elevated compared with the $\mathrm{TOSOH}$ assay.

We posted our concerns regarding falsely raised fT4 concentrations on the ACB mail base in February 2007 (Inc 017967 and 017509 found at https://www.jiscmail.ac.uk/ cgi-bin/webadmin?A2=ind0702\&L=ACB-CLIN-CHEM-GEN\& $\mathrm{P}=\mathrm{R} 20296)$ and were surprised that few other laboratories seemed to be experiencing the same problem. Roche responded to global customer complaints with the release, in 2008, of a new generation of their fT4 assay with reduced susceptibility to antiruthenium interference. Subsequently, we have detected only one falsely increased fT4. The sample in question came from a female patient and was analysed during the period of evaluation of the new generation fT4 assay. The fT4 results obtained by the old generation (lot 150353) and new generation assays (lot 151161) were 42.6 and $40.3 \mathrm{pmol} / \mathrm{L}$, respectively, with a TSH of $1.28 \mathrm{mIU} / \mathrm{L}$. Roche confirmed these findings and noted that lot 151161 resulted in only a slight decrease in the measured fT4 concentration. Analysis with a research 